\title{
Spatial and temporal variations of light rain events over China and the mid-high latitudes of the Northern Hemisphere
}

\author{
HUANG Gang $^{1 *} \&$ WEN GuanHuan ${ }^{2,3}$ \\ ${ }^{1}$ Key Laboratory of Regional Climate-Environment for East Asia, Institute of Atmospheric Physics, Chinese Academy of Sciences, \\ Beijing 100029, China; \\ ${ }^{2}$ Center for Monsoon System Research, Institute of Atmospheric Physics, Chinese Academy of Sciences, Beijing 100190, China; \\ ${ }^{3}$ Graduate University of Chinese Academy of Sciences, Beijing 100049, China
}

Received August 28, 2012; accepted November 2, 2012; published online January 11, 2013

\begin{abstract}
Based on observed daily precipitation data, monthly gridded radiosonde upper air temperature and sea surface temperature data from the UK Met Office Hadley Centre, monthly surface air temperature from the Climatic Research Unit at the University of East Anglia and the NCEP/NCAR monthly reanalysis data, this study investigates the spatial and temporal variations of light rain events over China and the mid-high latitudes of the Northern Hemisphere during 1961-2010, and discusses the relationship between the change of light rain events and atmospheric stability, sea surface temperature and atmospheric circulation. The light rain events over East China display a decreasing trend of 3.0\%/10 a in summer and winter half years. Over Northwest China, an increasing trend of $4.1 \% / 10$ a is found in winter half years, but there is no trend in summer half years. Using empirical orthogonal function (EOF) analysis, it is found that the first two principal components of light rain events over the mid-high latitudes of the Northern Hemisphere show long time scale variations in summer and winter half years. The first EOF modes (EOF1s) for summer and winter half years both depict a long-term increase in light rain events over North America and Southern Europe as well as Northwest China (except in summer half years), and a long-term decrease over most of the Eurasia (Central Europe, Eastern Europe, North Asia and East China). The second EOF mode (EOF2) for summer half year shows that light rain events increase over North America, Southern Europe and South China, but decrease over Eurasia north of $45^{\circ} \mathrm{N}$ from 1961 to early 1980 s, while the trends reverse from late 1980s to 2010. The second EOF mode (EOF2) for winter half years indicates that light rain events increase over North America and South and North China, but decrease over Eurasia north of $40^{\circ} \mathrm{N}$ from 1961 to early 1980 s, while the trends reverse from late 1980s to 2009. Correlation analysis and linear regression analysis suggest that EOF1s may be related to the change in atmospheric static stability associated with global warming, and EOF2s are possibly linked to the AMO.
\end{abstract}

light rain, the mid-high latitudes of the Northern Hemisphere, EOF, atmospheric stability, global warming

Citation: Huang G, Wen G H. Spatial and temporal variations of light rain events over China and the mid-high latitudes of the Northern Hemisphere. Chin Sci Bull, 2013, 58: 1402-1411, doi: 10.1007/s11434-012-5593-1

In recent decades, the global precipitation characteristic has changed significantly, following the continuous rise in the global temperature. In general, there have been increases in land precipitation at high latitudes, and deceases at the tropics and subtropics [1,2]. Precipitation in China as a whole has increased slightly since 1960 s, with strong regional and seasonal differences [3-6]. Regionally, precipitation increased in Northwest China, but decreased in North

*Corresponding author (email: hg@mail.iap.ac.cn)
China; seasonally, precipitation increased in winter and summer, but decreased in spring and autumn; precipitation extreme events increased in Northwest China and South China, but decreased in North China. Previous studies [7-12] mainly focused on the precipitation amount and extreme precipitation events, with little attention to the precipitation frequency, especially the light rain frequency. Trenberth [13] indicated that the characteristics of precipitation are just as vital as the total amount, and they are more apt to change as climate changes. Additionally, light rain events account for 
a large part of the precipitation events, while the proportion of extreme precipitation events is quite small $[14,15]$. Moreover, light rain soaks into the soil and benefit plants, while the heavy rain may cause local flooding and runoff, leaving soil much drier at the end $[1,13]$. Previous studies primarily investigated the long-term change of light rain in China. The results of Qian et al. [16] and Fu et al. [17] showed that the summer and annual light rain events $(<1$ $\mathrm{mm} / \mathrm{d}$ ) in East China decreased, and the change might be associated with global warming. However, the study of Qian et al. [18] suggested that the light rain decrease in East China be a result of air pollution. Furthermore, Liu et al. [19] found that precipitation events of $0.1-0.3 \mathrm{~mm} / \mathrm{d}$ decreased in whole China, and indicated that the reduction might be related with the decrease in solar radiation and cloud.

The changes of light rain events over large spatial region have not been well documented, although the decrease in light rain events in East China has been found. Therefore, this study is expected to analyze the spatial and temporal variations of light rain events over the Northern Hemisphere. Although Qian et al. [20] has investigated the long-term change of light rain over North America, Europe and Asia using Global Summary of Day (GSOD) dataset, the results have some uncertainties due to errors and a number of missing values in the dataset that consists of real-time data from Global Telecommunication System (GTS) [21,22]. This study investigates the spatial and temporal variations of light rain events over China and the mid-high latitudes of the Northern Hemisphere based on daily rain gauge precipitation data with quality control, and then discusses the probable causes of these changes.

\section{Data and methods}

\subsection{Data}

Data for this study consist of daily rain gauge precipitation dataset, monthly gridded radiosonde upper air temperature dataset [23] and sea surface temperature dataset [24] from the UK Met Office Hadley Centre (Hadley), monthly surface air temperature dataset [25] from the Climatic Research Unit at the University of East Anglia (CRU) and the NCEP/ NCAR monthly reanalysis dataset [26].

Daily rain gauge precipitation data includes Global Historical Climatology Network-Daily (GHCN-Daily) station precipitation dataset [21] from the National Climate Data Center (NCDC), European station precipitation dataset [27] from European Climate Assessment and Dataset (ECA\&D) project and Chinese station precipitation dataset from China Meteorological Administration (CMA). We replace the precipitation data over China and Europe in GHCN-Daily dataset with those from CMA and ECA\&D project, since the GHCN-Daily dataset contain fewer stations in China especially in western China and more missing values in China and Europe especially for some stations in China after late 1990s and for some European stations after 2000.

Monthly gridded radiosonde upper air temperature dataset has a horizontal resolution of $10^{\circ} \times 5^{\circ}, 9$ levels from 850 to $30 \mathrm{hPa}$, which is available starting in January 1958. Monthly sea surface temperature dataset has a horizontal resolution of $1^{\circ} \times 1^{\circ}$ and is available from January 1870 forward. Monthly surface air temperature has a horizontal resolution of $5^{\circ} \times 5^{\circ}$, available from January 1850 forward. The NCEP/NCAR monthly reanalysis dataset includes sea level pressure and air temperature on pressure levels (17 pressure levels from 1000 to $10 \mathrm{hPa}$ ), with a horizontal resolution of $2.5^{\circ} \times 2.5^{\circ}$ and covering the period of January 1948 to present.

\subsection{Data quality control}

In order to ensure the reliability of the results, the daily precipitation dataset is quality controlled. NCDC has applied a set of quality assurance procedures to GHCN-Daily dataset to detect duplicate data, climatological outliers and various inconsistencies. A detail description was documented by Durre et al. [28]. We remove the data errors failing in quality checks and retain the valid data. ECA\&D project has also checked the European station daily precipitation dataset and detected data errors including climatological outliers and negative values. We only use the data passing quality tests. Since the daily precipitation dataset from CMA hasn't been quality controlled by CMA, we detect the climatological outliers, negative values and world record exceedances referring to the quality checks applied to GHCN-Daily [28], and retain the valid data.

In this study, the year with no missing value is classified as usable. A station with no less than 40 usable years during 1961-2010 is accepted in this analysis. As a result, we select 3033 stations over the Northern Hemisphere, with 1135 stations from GHCN-Daily, 1276 stations from ECA\&D and 622 stations from CMA. The locations of these stations are shown in Figure 1. Since most of the stations locate over the mid-high latitudes of the Northern Hemisphere with a small number of exception at low latitudes $\left(0^{\circ}-30^{\circ} \mathrm{N}\right)$, the stations at low latitudes have not been excluded in this study.

\subsection{Methods}

CMA defines light rain as that with daily precipitation less than $10 \mathrm{~mm}$. The $10 \mathrm{~mm} / \mathrm{d}$ was also selected as the threshold for light rain in Qian et al.'s [18] and Qian et al.'s [20] investigations of the changes of light rain events over East China and North America, Europe and Asia. According to this definition, almost all the stations' light rain events in climatological mean account for more than $50 \%$ of precipitation events over the mid-high latitudes of the North Hemisphere, with $50 \%-80 \%$ at mid latitudes and more than $90 \%$ at high latitudes and Northwest China (figure not shown). Therefore, a fixed threshold to define light rain may not be 


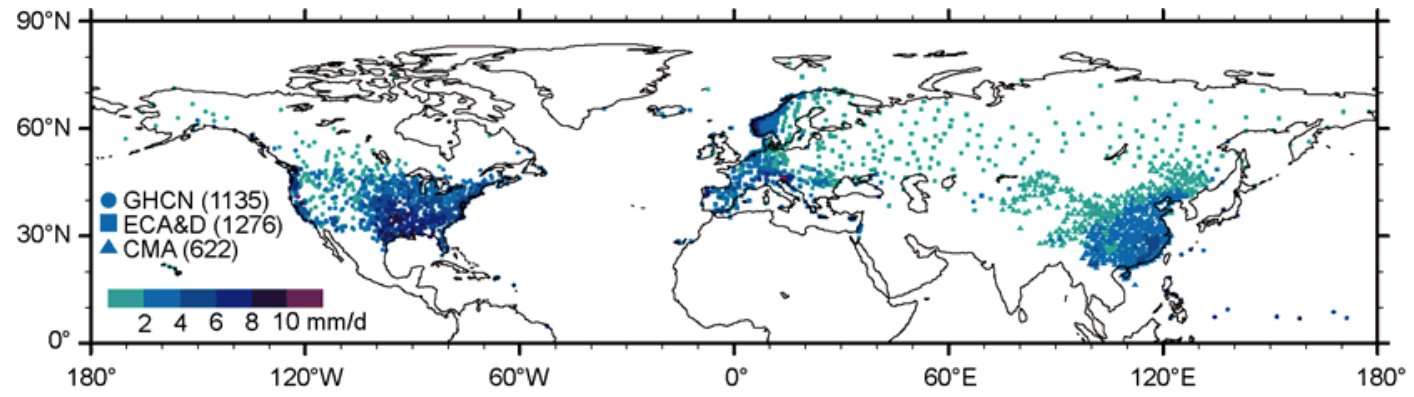

Figure 1 The locations of 3033 precipitation stations and the thresholds for light rain events (the 50th percentile, mm/d). Circles, squares and triangles denote stations from GHCN-Daily, ECA\&D, CMA, respectively.

appropriate. Considering regional differences in precipitation, we use percentile threshold to define light rain. The 50th percentile, which is the smallest percentage (47\% actually) of precipitation days of less than $10 \mathrm{~mm} / \mathrm{d}$ accounting for all the precipitation days in all stations, is chosen to be the threshold for light rain. Here, we want to point out that similar results are obtained when the analysis is based on the 30th or 40th percentile. For a station, if the daily precipitation is less than the threshold, then the precipitation event on that day is regarded as a light rain event. We refer to the method of Bonsal et al. [29] and Zhai et al. [30] to calculate the 50th percentile value. Daily precipitation during 1961-1990 is first ranked in ascending order $x_{1}, x_{2}, \cdots$, $x_{m}, \cdots, x_{n}$. The probability $P$ that a random value is less than or equal to the rank of that value $x_{m}$ is estimated by the equation of $p=(m-0.31) /(n+0.38)$, in which $m$ is the sequence number of $x_{m}$. The 50th percentile value is the $x_{m}$ when $m$ makes $p$ equal 50\%. The thresholds for light rain event of every station are shown in Figure 1, ranging from $6-12 \mathrm{~mm} / \mathrm{d}$ in Southeast United States, $2-6 \mathrm{~mm} / \mathrm{d}$ in Southeast China and less than $2 \mathrm{~mm} / \mathrm{d}$ over most of the mid-high latitudes of the Northern Hemisphere.

Considering the seasonal differences of climate background, this study divides a year into summer half year and winter half year, and analyzes the changes of light rain events in summer and winter half years respectively. Same as the study of Zhai et al. [6], summer half year is from April to September and winter half years is from October to March in the next year.

Linear regression is used to analyze the long-term trends in light rain events over China. Empirical orthogonal function (EOF) analysis is employed to obtain the first two dominant EOF modes and principal components of the light rain events over the mid-high latitudes of the Northern Hemisphere. Like the method of Wu et al. [31], the EOF modes and principal component, are multiplied by the square root of the eigenvalues and the reciprocal of the square root of eigenvalues, respectively. Linear regression and correlation analysis are applied to the investigations of the relationship between the change of light rain events and atmospheric stability, sea surface temperature and atmospheric circulation. The Student's $t$-test is used to examine the significance of the linear regression and correlation.

\section{Results and discussion}

\subsection{Long-term trends in light rain events over China}

Previous studies [16-18] mainly focused on the decrease in light rain events over East China, while the change in the rest of China was less studied. Moreover, fixed threshold was often used to define light rain. In this analysis, the changes of light rain events in summer and winter half years based on percentile thresholds are investigated over whole China.

Figure 2(a) shows the long-term trends in light rain events of 622 stations over China for summer half years during 1961-2010. Decreasing trends in light rain events are obvious in East China (east of $100^{\circ} \mathrm{E}$ ). Although more stations in Northwest China (west of $100^{\circ} \mathrm{E}$, north of $30^{\circ} \mathrm{N}$ ) have upward trends, most of the trends are not statistically significant. The regionally averaged light rain events in East China has a decreasing trend of $0.9 \mathrm{~d} / 10 \mathrm{a}$ or equivalently $3.0 \% / 10$ a (Figure 2(b)), which exceeds the $99 \%$ confidence level; while there is no significant tendency in regionally averaged light rain events over Northwest China (Figure 2(c)).

Figure 2(d) is the same as Figure 2(a) but for the winter half years during 1961-2009. The light rain events for winter half years in East China primarily exhibit decreasing trends, although the trends for some stations over northern China are not statistically significant and a small number of stations in Northeast China show increasing trends. However, the light rain events for most of the stations in Northwest China have increasing trends. The trend in regionally averaged light rain events in East China is $-0.8 \mathrm{~d} / 10$ a corresponding to $-3.0 \% / 10$ a (Figure 2(e)), and that in Northwest China is $0.6 \mathrm{~d} / 10$ a or $4.1 \% / 10$ a, which both exceed the $99 \%$ confidence level (Figure 2(f)).

\subsection{Spatial and temporal variations of light rain events over the mid-high latitudes of the Northern Hemisphere}

The EOF analysis is applied to the light rain days of 3303 

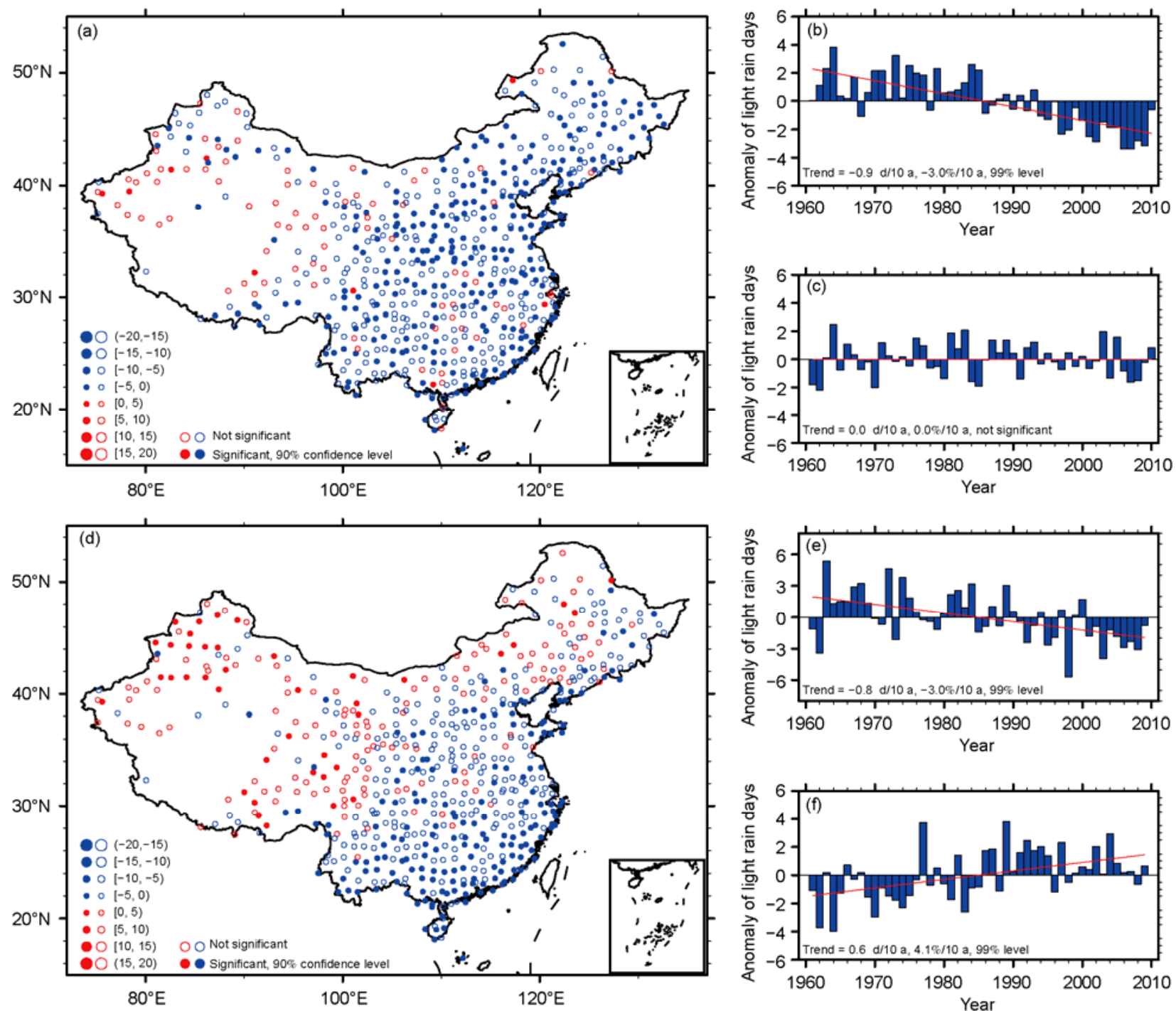

Figure 2 Trends (d/10 a) in light rain days of 622 stations over China (a) and light rain day anomalies (d) averaged over East China (east of $\left.100^{\circ} \mathrm{E}\right)(\mathrm{b})$ and Northwest China (c) in summer half years during 1961-2010. (d), (e) and (f) are the same as (a), (b) and (c), respectively, but for winter half years.

stations over the mid-high latitudes of the Northern Hemisphere in summer and winter half years during 1961-2009 respectively. The first two EOF modes and the corresponding principal components for summer and winter half years, which explain about $10.2 \%$ and $5.2 \%$ of the total variances for summer half years and $10.3 \%$ and $6.5 \%$ for winter half years, are shown in Figure 3.

The first two principal components (PCs) for summer half years indicate slow variations of light rain events (Figure 3(c)). PC1 represents the long-term trends during 19612010 and, PC2 depicts the two opposite trends during 1961 to early 1980 s and during late 1980 s to 2010 . The first EOF mode (EOF1, Figure 3(a)) for summer half years is characterized by a positive anomaly covering North America, Southern Europe and a negative anomaly covering most of the Eurasia including Central and Eastern Europe, North Asia (east of the Urals, about east of $60^{\circ} \mathrm{E}$ ) and East China. As mentioned above, the corresponding principal compo- nent $(\mathrm{PC} 1)$ represents the long-term trends in recent 50 years. Therefore, the EOF1 and PC1 indicate that the light rain events in summer half years increase over North America and Southern Europe during 1961-2010, but decrease over most of the Eurasia (Central and Eastern Europe, North Asia and East China), especially in East China. The second EOF mode (EOF2, Figure 3(b)) for summer half years is characterized by a negative anomaly in North America, Southern Europe and South China and a positive anomaly over Eurasia north of $45^{\circ} \mathrm{N}$. The second principal component (PC2) depicts a decreasing trend from 1961 to early 1980s and an increasing trend from late 1980s to 2010. Hence, the EOF2 and PC2 reveal that the light rain events in summer half years increase in North America, Southern Europe and South China during 1961 to early 1980s, but decrease over Eurasia north of $45^{\circ} \mathrm{N}$; the trends reverse in these areas during late 1980 s to 2010 .

The leading two principal components of light rain events 

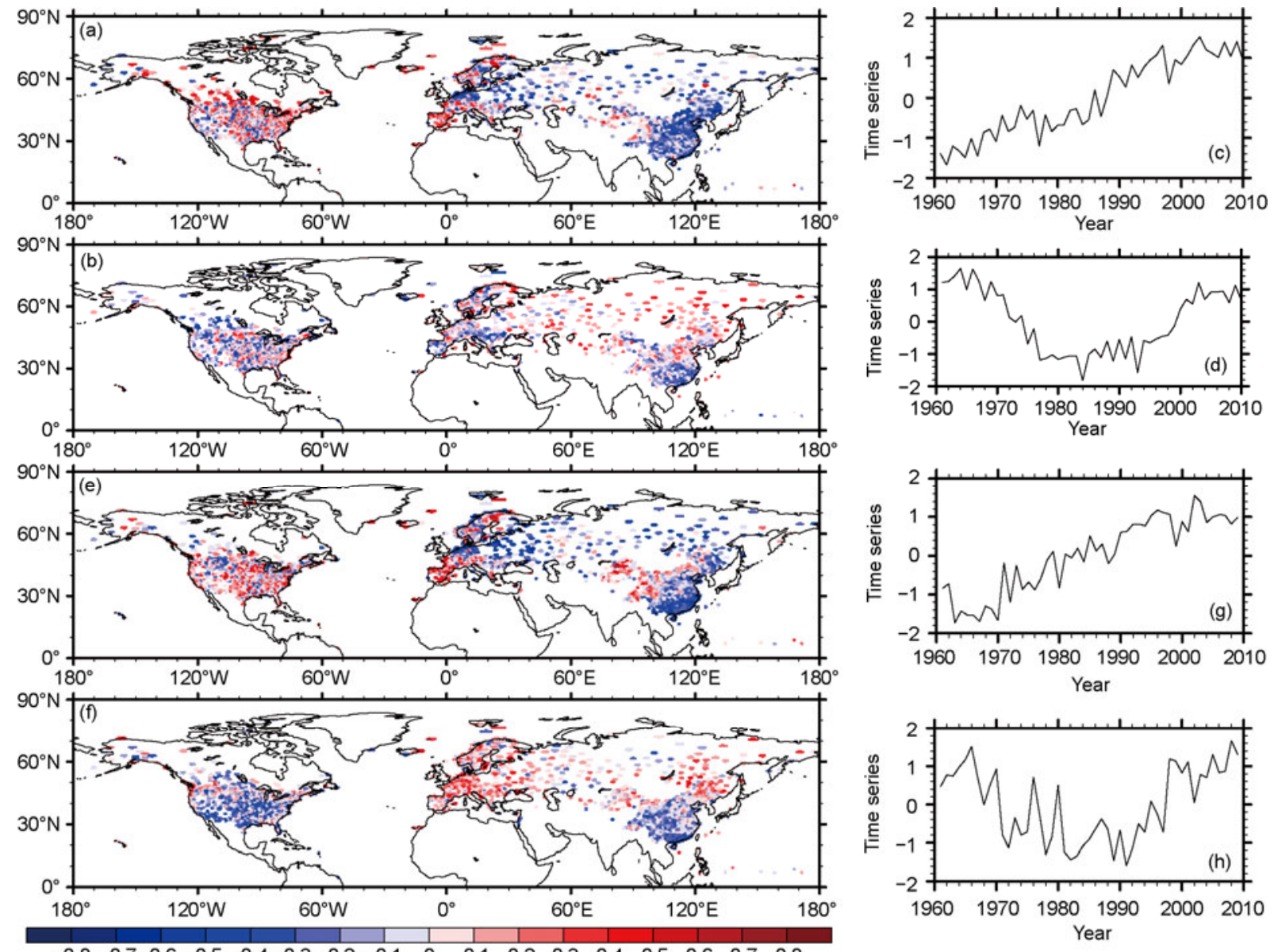

Figure 3 The first EOF mode (a) and the second EOF mode (b) of light rain days over the mid-high latitudes of the North Hemisphere and the first principal components (c) and the second principal components (d) for summer half years during 1961-2010. (e), (f), (g) and (h) are the same as in (a), (b), (c) and (d), respectively, but for winter half years.

in winter half years are similar to those for summer half years respectively, with PC1 (Figure 3(g)) depicting longterm change and PC2 (Figure 3(h)) describing opposite trends during periods of 1961 to early 1980s and late 1980s to 2009. The first EOF mode (EOF1, Figure 3(e)) for winter half years is also similar to that for summer half years except for Northwest China where the long-term change of light rain events is significant. The EOF1 for winter half years is characterized by a positive anomaly covering North America, Southern Europe and Northwest China and a negative anomaly covering most of the Eurasia (Central and Eastern Europe, North Asia and East China). This indicates that the light rain events in winter half years increase over North America, Southern Europe and Northwest China during 1961-2010, but decrease over most of Eurasia (Central and Eastern Europe, North Asia and East China). The second EOF mode (EOF2, Figure 3(f)) for winter half years is analogous to that for summer half years except for Southern Europe, where the change for winter half years is contrary to summer half years. The EOF2 for winter half years shows a negative anomaly in North America, South and North China and a positive anomaly over Eurasia north of $40^{\circ} \mathrm{N}$. This implies that the light rain events in winter half years increase in North America, South and North China during 1961 to early 1980s, and decrease over Eurasia north of $40^{\circ} \mathrm{N}$; the trends reverse in these areas during late 1980s to 2009 .

\subsection{Discussion}

Precipitation events are generally accompanying upward motions. The vertical motion is usually associated with the atmospheric stratification, in other words, it is associated with the vertical distribution of atmospheric temperature and humidity. Unstable atmospheric stratification favors upward motion and heavy precipitation, while stable atmospheric stratification suppresses the upward motion and is unfavorable for intense precipitation [32]. Thus the change of atmospheric static stability may influence the change of light rain events. While the atmospheric stability strengthens, the upward motion abates so that the precipitation intensity decreases and light rain events increase. When the atmospheric stability weakens, the upward motion strengthens so that the precipitation intensity increases and 
light rain events decrease. As mentioned above, the first principal component of light rain events in both summer and winter half years represent the long-term trend during 1961-2010. This section mainly investigates the relationship between the trend of light rain events and the atmospheric stability over the mid-high latitudes of the Northern Hemisphere.

Figure 4(a) and (b) shows the trend of lower troposphere temperature difference between lower and upper level in summer half years during 1961-2010, based on reanalysis air temperature from the NCEP/NCAR and upper radiosonde temperature from Hadley Centre, surface air temperature from CRU, respectively. The result from NCEP/ NCAR reanalysis air temperature (Figure 4(a)) indicates that the temperature difference between 1000 and $700 \mathrm{hPa}$ decrease over the mid latitudes of North America in recent 50 years, where the temperature difference between surface air temperature from CRU and radiosonde temperature at $700 \mathrm{hPa}$ from Hadley Center (Figure 4(b)) also shows a decreasing trend. Thus, both datasets imply that the atmospheric stability strengthens over the mid latitudes of North America. As mentioned above, the light rain events for summer half years increase over North America. The air temperature differences between lower level and upper level decrease and the atmospheric stability weakens over Central and Eastern Europe, North Asia and East China (Figure 4(a), (b)), where the light rain events decrease. The air temperature differences in winter half years from reanalysis data
(Figure 4(d)) and from CRU data and Hadley Centre radiosonde data (Figure 4(e)) have decreasing trends over the mid latitudes of North America and Southern Europe (not shown in Figure 4(d) for statistical significance). This indicates that the atmospheric stability strengthens. The air temperature differences in winter half years have increasing trends over Central and Eastern Europe, North Asia and East China (except for South China in reanalysis data) based on CRU and Hadley Centre data (Figure 4(e)) and the NCEP/NCAR reanalysis data (Figure 4(d)). This corresponds to the light rain events decrease over Central and Eastern Europe, North Asia and East China. The reanalysis data (Figure 4(d)) show that the temperature differences between lower and upper level in winter half years decrease and the atmospheric stability strengthens over South and Northwest China, while the observed data (Figure 4(e)) indicate that the atmospheric stability weakens over South and Northwest China. The contrary results from different data make it difficult to verify the association between the change of light rain events and atmospheric stability over South and Northwest China. From the above analysis, in most of the areas light rain events increase when atmospheric stability strengthens and light rain events decrease when atmospheric stability weakens. However, there are still some exceptions. For example, the air temperature difference between surface and $700 \mathrm{hPa}$ in summer half years based on observed data increase and atmospheric stability weakens over Southern Europe (Figure 4(b)), but the light
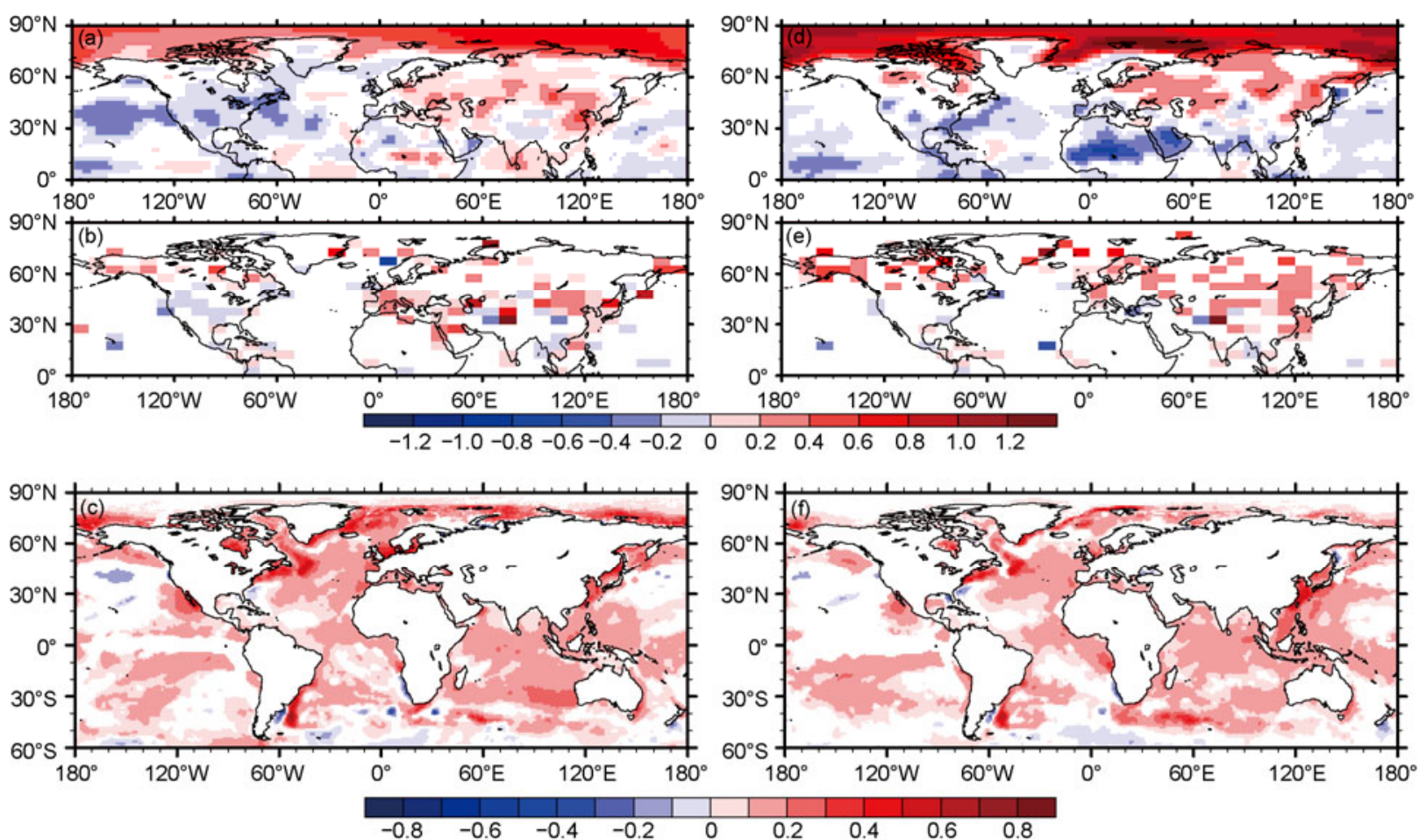

Figure 4 Trends $\left({ }^{\circ} \mathrm{C} / 10\right.$ a) in air temperature difference between 1000 and $700 \mathrm{hPa}$ based on NCEP/NCAR Reanalysis air temperature (a) and between surface and $700 \mathrm{hPa}$ based on surface air temperature from CRU and radiosonde upper air temperature from Hadley Centre (b), and trends (K/10 a) in global sea surface temperature (c) in summer half years during 1961-2010. (d), (e) and (f) are the same as in (a), (b) and (c), respectively, but for winter half years. Shaded areas denote $90 \%$ confidence level. 
rain events increase. So the change may be influenced by other factors. This study primarily discusses the probable causes for the change of light rain events on large spatial scale, and the local factors are not our concern in this study. The cause for the change of precipitation pattern on local scale may be complicated. We will investigate the local cause in the near future.

The trends in sea surface temperature for summer and winter half years are shown in Figure 4(c) and Figure 4(f), respectively. A number of studies [2,33-35] have pointed out that the Earth surface (sea and land surface) and troposphere temperatures continuously increase. Following the increase in sea surface temperature, the evaporation increases and more water vapor would be in the atmosphere. The latent heat from more water vapor condensation makes the upper air become warmer. Meanwhile, the Earth surface warming makes the surface air temperature increase. However, the magnitudes of warming of lower and upper air are different in different area. So the atmospheric stability changes, which induce the change in light rain events.

In addition, the present analysis indicates an increase in light rain events for summer and winter half years over North America and Southern Europe, which is different from the result of Qian et al. [20] who showed that the light rain events decrease over North America and Europe (including Southern Europe). Their results may be associated with too high threshold for light rain event and too much missing values (less than $10 \%$ of annual days, which is 36 d/a) in the used data.

A number of studies [36-42] have revealed the connection between the precipitation or extreme precipitation events and sea surface temperature and atmospheric circula- tion. In order to investigate the relationship between the second EOF mode of light rain events and sea surface temperature and atmospheric circulation, we calculate respectively the correlation coefficient between the PC2 of the light rain events in summer and winter half years and global sea surface temperature (SST) and sea level pressure (SLP), which are shown in Figure 5. It can be seen from Figure 5(a) and (c) that high correlation between PC2 and SST are mainly located in North Atlantic and North Pacific in summer and winter half years. North Atlantic sea surface temperature has multidecadal variation, which is known as Atlantic Multidecadal Oscillation (AMO). The AMO can impact the climate of North America, Europe and Asia [43-46]. We calculate the correlation coefficient between AMO index [47] and PC2 for summer and winter half years. The coefficients are 0.56 and 0.76 , respectively, exceeding the $99 \%$ confidence level (correlation coefficient of 0.36).

The observation and simulation results of previous studies $[45,46,48]$ showed that during the AMO warm phase, the summer rainfall and river flows decrease in North America, while summer precipitation increase in Europe, which implies that there are negative correlation between the AMO and summer precipitation in North America and positive correlation in Europe. The AMO was changing from warm phase to cold phase during 1961 to early 1980s and from cold phase to warm phase after late 1980s (figure not shown), which is similar to the change of PC2. As mentioned above, the second EOF mode of light rain events in summer half years indicates that light rain events increase over North America and decrease over Europe (except for Southern Europe) during 1961 to early 1980s, while the trends reverse after late 1980s. Therefore, there are negative
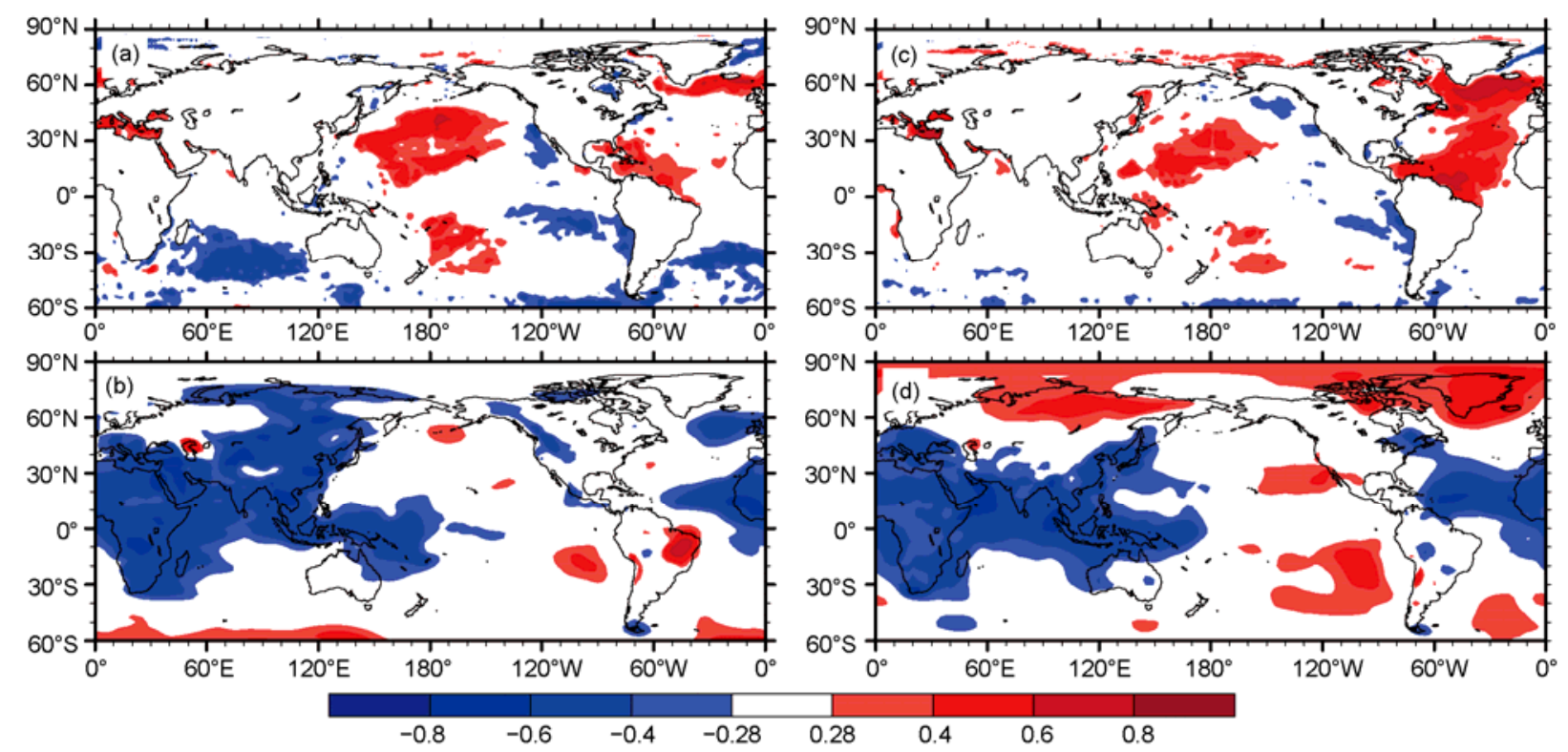

Figure 5 Correlation coefficient between the second principal component of the light rain days and sea surface temperature (a) and sea level pressure (b) in summer half years during 1961-2010. (c) and (d) are the same as in (a) and (b), respectively, but for winter half years. Shaded areas denote 95\% confidence level. 
correlation between the AMO and the second EOF mode of light rain events in summer half years over North America and positive correlation over most of Europe. Sutton et al. [45] found that there are two low-pressure anomaly centers over North Atlantic during the AMO warm phase, one located to the southwest of United States, the other being to the west of Europe, and indicated that the two anomaly centers were associated with the precipitation change over North America and Europe. It can be seen from the pattern of the correlation between PC2 and sea level pressure (Figure 5(b)) that there are two significant correlative regions over North Atlantic, with the northern one corresponding to the anomaly center to the west of Europe, and the southern one located in the North Atlantic to the southwest of United States, to the southeast of the anomaly center. Thus, the AMO is probably linked to the second EOF mode of light rain events for summer half years over North America and Europe. The AMO influences the change of precipitation and precipitation days, and the change of light rain events probably keeps in line with the change of precipitation and precipitation days. Therefore, the second EOF mode of light rain events displays opposite trends in two periods. However, whether the change of light rain events is accordance with precipitation and precipitation days or not should be investigated further. Using observed precipitation data, $\mathrm{Li}$ et al. [44] and Wang et al. [43] found that during the AMO warm phase, the autumn and winter precipitation decrease in South China. The result indicates that there is negative correlation between the AMO and autumn and winter precipitation in South China, which is in accordance with the fact that South China is covering negative anomaly in EOF2 for winter half years. However, the mechanism how AMO influences the East Asian climate is not clear, and should be studied onward [49]. Although no research revealed the connection between the AMO and autumn and winter precipitation over North America and Europe, Knight et al.'s model results [48] showed that the AMO was directly related to autumn and winter precipitation over Europe, in agreement with the fact that Europe is covering positive anomaly in EOF2 for winter half years. Their results also indicated that the AMO was negatively correlated with the autumn and winter sea level pressure, which is similar to the pattern of correlation between PC2 and sea surface pressure in winter half years (Figure 5(d)). Thus, the AMO is possibly associated with the second mode of light rain events in winter half years. It should be noted that the AMO is a multidecadal oscillation with a cycle of 65-80 years [49], but the temporal period in this study is only 50 years, which is less than a cycle of the AMO. Therefore, longer precipitation data is needed to verify the association between the $\mathrm{AMO}$ and the second EOF mode of light rain events.

The North Pacific sea surface temperature decreased during 1961 to early 1980 s, and increased after late 1980s (figure not shown). Thus PC2 of light rain events in summer and winter half years is positively correlated with the North
Pacific sea surface temperature. Nevertheless, we have not found the probable connection between the North Pacific sea surface temperature and the second EOF mode of light rain events. Aleutian low weakens during North Pacific warm phase and strengthens during cold phase [50]. Nevertheless, there is no significant correlation between PC2 for summer and winter half years and Aleutian low (Figure 5(b), (d)). In addition, the precipitation in coastal Southeast China increases during warm phase and decreases during cold phase [51,52]. The positive correlation disagrees with the negative anomaly in coastal Southeast China in EOF2 (Figure 3(b),(f)). Thus, it could not be determined that the change of light rain events is in accordance with the change of precipitation and precipitation days.

\section{Summary}

This study investigates the long-term trend in light rain events over China in summer and winter half years during 1961-2010 based on daily precipitation data of 622 stations. The results show that the light rain events over East China in summer and winter half years decrease significantly by $0.9 \mathrm{~d} / 10 \mathrm{a}$ and $0.8 \mathrm{~d} / 10$ a corresponding to $3 \% / 10$ a respectively, while those in Northwest China increase by $0.6 \mathrm{~d} / 10$ a corresponding to $4.1 \% / 10$ a in winter half years, but display no trend in summer half years.

In order to study the change of light rain events on large spatial scale, this investigation uses EOF analysis to obtain the first two EOF modes and corresponding principal components of light rain events in summer and winter half years, based on station daily precipitation data over the mid-high latitudes of the Northern Hemisphere. The first two principal components (PCs) for summer and winter half years are characterized by long time scale changes, with PC1 for summer and winter half years both representing long-term trend during 1961 to 2010 and PC2 for summer and winter half years both standing for opposite trends during periods of 1961 to early 1980 s and late 1980 s to 2010 . The first EOF modes (EOF1) for summer and winter half years both primarily depict that the light rain events increase over North America and Southern Europe and decrease over most of Eurasia (including Central and Eastern Europe, North Asia and East China) during 1961-2010. The EOF1 for winter half years also shows that the light rain events increase in Northwest China. The second EOF mode (EOF2) for summer half years reveals that the light rain events increase over North America, Southern Europe and South China during 1961 to early 1980s, and decrease over Eurasia north of $45^{\circ} \mathrm{N}$, while the trends reverse after late $1980 \mathrm{~s}$. The second EOF mode (EOF2) for winter half years indicates that the light rain events increase over North America, South and North China during 1961 to early 1980s, and decrease over Eurasia north of $40^{\circ} \mathrm{N}$, while the trends reverse after late 1980s. 
This study discusses the probable cause for the change of light rain events. The relationship between the pattern of the trend in atmospheric stability and the trend in light rain events depicted in EOF1 indicate that in most areas the light rain events increase when atmospheric stability strengthens, and decrease when atmospheric stability weakens. The long-term change of atmospheric stability is a probable cause for the long-term change of light rain events. The change of atmospheric stability is possibly related to different vertical warming of troposphere associated with global warming. The second EOF modes may be linked to the AMO. Nevertheless, the influencing mechanism is not clear, and needs to be investigated further.

This work was supported by the National Basic Research Program of China (2012CB955604 and 2011CB309704), the Strategic Priority Research Program of the Chinese Academy of Sciences (XDA05090402), and the National Natural Science Foundation of China (41275083). The authors would like to thank Prof. Wu Renguang and two anonymous reviewers as well as editors for their useful comments.

1 Trenberth K E. Changes in precipitation with climate change. Clim Res, 2011, 47: 123-138

2 Trenberth K E, Jones P D, Ambenje P, et al. Observations: Surface and atmospheric climate change. In: Solomon S, Qin D, Manning M, et al., eds. Climate Change 2007: The Physical Science Basis. Cambridge, United Kingdom and New York: Cambridge University Press, 2007. 235-336

3 Ma Z G, Fu C B. Some evidences of drying trend over North China from 1951 to 2004. Chin Sci Bull, 2006, 51: 2913-2925

4 Liu B H, Xu M, Henderson M, et al. Observed trends of precipitation amount, frequency, and intensity in China, 1960-2000. J Geophys Res, 2005, 110: D08103

5 Wang Y Q, Zhou L. Observed trends in extreme precipitation events in China during 1961-2001 and the associated changes in large-scale circulation. Geophys Res Lett, 2005, 32: L17708

6 Zhai P M, Zhang X B, Wan H, et al. Trends in total precipitation and frequency of daily precipitation extremes over China. J Clim, 2005, 18: $1096-1108$

7 Li J, Dong W J, Yan Z W. Changes of climate extremes of temperature and precipitation in summer in eastern China associated with changes in atmospheric circulation in East Asia during 19602008. Chin Sci Bull, 2012, 57: 1856-1861

8 Chen F H, Huang W, Jin L Y, et al. Spatiotemporal precipitation variations in the arid Central Asia in the context of global warming. Sci China Earth Sci, 2011, 54: 1812-1821

9 Zolina O, Simmer C, Belyaev K, et al. Improving estimates of heavy and extreme precipitation using daily records from European rain gauges. J Hydrometeor, 2009, 10: 701-716

10 Alexander L V, Zhang X, Peterson T C, et al. Global observed changes in daily climate extremes of temperature and precipitation. $\mathrm{J}$ Geophys Res, 2006, 111: D05109

11 Easterling D R, Evans J L, Groisman P Y, et al. Observed variability and trends in extreme climate events: A brief review. Bull Am Meteorol Soc, 2000, 81: 417-425

12 Karl T R, Knight R W. Secular trends of precipitation amount, frequency, and intensity in the United States. Bull Am Meteorol Soc, 1998, 79: 231-241

13 Trenberth K E, Dai A, Rasmussen R M, et al. The changing character of precipitation. Bull Am Meteorol Soc, 2003, 84: 1205-1217

14 Michaels P J, Knappenberger P C, Frauenfeld O W, et al. Trends in precipitation on the wettest days of the year across the contiguous USA. Int J Climatol, 2004, 24: 1873-1882
15 Groisman P Y, Karl T R, Easterling D R, et al. Changes in the probability of heavy precipitation: Important indicators of climatic change. Clim Change, 1999, 42: 243-283

16 Qian W H, Fu J K, Yan Z W. Decrease of light rain events in summer associated with a warming environment in China during 1961-2005. Geophys Res Lett, 2007, 34: L11705

17 Fu J L, Qian W H, Lin X, et al. Trends in graded precipitation in China from 1961 to 2000. Adv Atmos Sci, 2008, 25: 267-278

18 Qian Y, Gong D Y, Fan J W, et al. Heavy pollution suppresses light rain in China: Observations and modeling. J Geophys Res, 2009, 114: $\mathrm{D} 00 \mathrm{~K} 02$

19 Liu B, Xu M, Henderson M. Where have all the showers gone? Regional declines in light precipitation events in China, 1960-2000. Int J Climatol, 2010, 31: 1177-1191

20 Qian Y, Gong D Y, Leung R. Light rain events change over North America, Europe, and Asia for 1973-2009. Atmos Sci Lett, 2010, 11: 301-306

21 Menne M J, Durre I, Vose R S, et al. An overview of the global historical climatology network-daily database. J Atmos Oceanic Technol, 2012, 29: 897-910

22 Yatagai A, Arakawa O, Kamiguchi K, et al. A 44-year daily gridded precipitation dataset for Asia based on a dense network of rain gauges. SOLA, 2009, 5: 137-140

23 Thorne P W, Parker D E, Tett S F B, et al. Revisiting radiosonde upper air temperatures from 1958 to 2002. J Geophys Res, 2005, 110: D18105

24 Rayner N A, Parker D E, Horton E B, et al. Global analyses of sea surface temperature, sea ice, and night marine air temperature since the late nineteenth century. J Geophys Res, 2003, 108: 4407

25 Jones P D, Lister D H, Osborn T J, et al. Hemispheric and large-scale land surface air temperature variations: An extensive revision and an update to 2010. J Geophys Res, 2012, 117: D05127

26 Kalnay E, Kanamitsu M, Kistler R, et al. The NCEP/NCAR 40-year reanalysis project. Bull Am Meteorol Soc, 1996, 77: 437-471

27 Klein Tank A M G, Wijngaard J B, Können G P, et al. Daily dataset of 20th-century surface air temperature and precipitation series for the European climate assessment. Int J Climatol, 2002, 22: 14411453

28 Durre I, Menne M J, Gleason B E, et al. Comprehensive automated quality assurance of daily surface observations. J Appl Meteor Climatol, 2010, 49: 1615-1633

29 Bonsal B R, Zhang X, Vincent L A, et al. Characteristics of daily and extreme temperatures over Canada. J Clim, 2001, 14: 1959-1976

30 Zhai P M, Pan X H. Change in extreme temperature and precipitation over northern China during the second half of the 20th century (in Chinese). Acta Geograph Sin, 2003, 58: 1-10

$31 \mathrm{Wu} \mathrm{H} \mathrm{B}, \mathrm{Wu}$ L. Methods for Diagnosis and Forecasting Climate Variability (in Chinese). Beijing: Meteorological Press, 2005. 15-33

32 Chen Y S, Jiang R B. Meteorology (in Chinese). Beijing: Meteorological Press, 1989. 206-207

33 Hansen J, Sato M, Ruedy R, et al. Global temperature change. Proc Natl Acad Sci USA, 2006, 103: 14288-14293

34 Mears C A, Wentz F J. The effect of diurnal correction on satellite-derived lower tropospheric temperature. Science, 2005, 309: $1548-1551$

35 Vinnikov K Y, Grody N C. Global warming trend of mean tropospheric temperature observed by satellites. Science, 2003, 302: 269-272

36 Zhou B T. Linkage between winter sea surface temperature east of Australia and summer precipitation in the Yangtze River valley and a possible physical mechanism. Chin Sci Bull, 2011, 56: 1821-1827

37 Yang F L, Lau K M. Trend and variability of China precipitation in spring and summer: Linkage to sea-surface temperatures. Int $\mathbf{J}$ Climatol, 2004, 24: 1625-1644

38 Lau K M, Lee J Y, Kim K M, et al. The North pacific as a regulator of summertime climate over Eurasia and North America. J Clim, 2004, 17: 819-833

39 Zhang Y L, Ding Y G. The teleconnection between summer extreme precipitation over East China and North Pacific SST (in Chinese). J 
Nanjing Inst Meteorol, 2004, 35: 244-252

40 Ye H. Characteristics of winter precipitation variation over northern Central Eurasia and their connections to sea surface temperatures over the Atlantic and Pacific oceans. J Clim, 2001, 14: 3140-3155

41 Higgins R W, Schemm J K E, Shi W, et al. Extreme precipitation events in the western United States related to tropical forcing. J Clim, 2000, 13: 793-820

42 Ting M, Wang H. Summertime US precipitation variability and its relation to Pacific sea surface temperature. J Clim, 1997, 10: 18531873

43 Wang Y, Li S, Luo D. Seasonal response of Asian monsoonal climate to the Atlantic multidecadal oscillation. J Geophys Res, 2009, 114: D02112

$44 \mathrm{Li} \mathrm{S}$, Bates G. Influence of the Atlantic multidecadal oscillation on the winter climate of East China. Adv Atmos Sci, 2007, 24: 126-135

45 Sutton R T, Hodson D L R. Atlantic ocean forcing of North American and European summer climate. Science, 2005, 309: 115118
46 Enfield D B, Mestas, Nuñez A M, et al. The Atlantic multidecadal oscillation and its relation to rainfall and river flows in the continental U.S. Geophys Res Lett, 2001, 28: 2077-2080

47 Trenberth K E, Shea D J. Atlantic hurricanes and natural variability in 2005. Geophys Res Lett, 2006, 33: L12704

48 Knight J R, Folland C K, Scaife A A. Climate impacts of the Atlantic multidecadal oscillation. Geophys Res Lett, 2006, 33: L17706

49 Li S L, Wang Y M, Gao Y Q. A review of the researches on the Atlantic Multidecadal Oscillation (AMO) and its climate influence (in Chinese). Trans Atmos Sci, 2009, 23: 458-465

50 Latif M, Barnett T P. Decadal climate variability over the North Pacific and North America: Dynamics and predictability. J Clim, 1996, 9: 2407-2423

51 Wu B Y, Zhang R H. Interdecadal shift in the wester North Pacific summer SST anomally in the late 1980s. Chin Sci Bull, 2007, 52: 2559-2564

52 Li C Y, Zhu J H, Sun Z B. The study interdecadal climate variation (in Chinese). Clim Environ Res, 2002, 7: 209-219

Open Access This article is distributed under the terms of the Creative Commons Attribution License which permits any use, distribution, and reproduction in any medium, provided the original author(s) and source are credited. 